\title{
Detecting Idiographic Personality Change
}

\author{
Emorie D. Beck \\ Northwestern University Feinberg School of Medicine \\ Joshua J. Jackson \\ Washington University in St. Louis
}

Correspondence concerning this article should be addressed to Emorie D Beck, 633 N St.

Clair St., Chicago, IL 60611. Email: emorie_beck@ northwestern.edu.

Emorie Beck was supported by National Institute on Aging Grants T32 AG00030-3, 5R01AG067622-02, and 5R01AG018436-20. Open materials on GitHub (https://github.com/emoriebeck/KCP) and the Open Science Framework (https://osf.io/mfn8w/) contain results and code used to conduct the analyses in this manuscript as well as a number of additional analyses. This study was preregistered on the Open Science Framework (https://osf.io/zbkta). 


\begin{abstract}
Personality changes across the lifespan, but strong evidence regarding the mechanisms of personality change remains elusive. Studies of personality change and life events, for example, suggest that personality is difficult to change. But there are two key issues with assessing personality change. First, most change models optimize population-level, not individual-level, effects, which ignores heterogeneity in patterns of change. Second, optimizing change as meanlevels of self-reports fails to incorporate methods for assessing personality dynamics, such as using changes in variances of multivariate time series data that often proceed changes in meanlevels, making variance change detection a promising technique for the study of change. Using a sample of $\mathrm{N}=388$ participants (total $\mathrm{N}=21,790$ ) assessed weekly over 60 weeks, we test a permutation-based approach for detecting individual-level personality changes in multivariate time series and compare the results to event-based methods for assessing change. We find that a non-trivial number of participants show change over the course of the year but that there was little association between these change points and life events they experienced. We conclude by highlighting the importance in idiographic and dynamic investigations of change.
\end{abstract}

Keywords: personality, change, idiographic, dynamics, time series 


\section{Detecting Idiographic Personality Change}

Personality traits are temporally stable, dispositional patterns that differentiate people from one another (Roberts, Wood, \& Caspi, 2008). Despite this consistency, personality is characterized by both continuity and change (Roberts \& Mroczek, 2007), which are typically assessed using three metrics. First, many personality traits exhibit high levels of rank-order consistency over long periods of time (Damien, Spengler, Sutu, \& Roberts, 2019; Roberts \& DelVecchio, 2000; Specht, Egloff, \& Schmukle, 2011; Terracciano, Costa Jr, \& McCrae, 2006). Despite this rank-order consistency, mean-level (i.e. normative) changes in personality traits occur throughout the lifespan (McCrae et al., 2002; Roberts, Walton, \& Viechtbauer, 2006; Robins et al., 2001; Soto \& John, 2012). However, among these normative patterns are considerable individual differences in the direction and rate of change (Mroczek \& Spiro, 2003; Roberts \& Mroczek, 2008). These three types of patterns - consistency, mean-level change, and individual differences in change - are the most studied types of personality development. Common among all three is a between-person, nomothetic assessment of personality.

However, a growing body of research suggests the importance of examining other types of personality change, as the focus on these types does not provide clarity on what experiences are driving personality change (Jackson \& Beck, 2021). For example, while studies find that people who experience life events like marriage (Specht et al., 2011) are associated with meanlevel change, research that accounts for selection bias suggests that life events' influence on mean-level personality change may be smaller than initially thought. In at least two studies, accounting for selection bias drastically reduces the amount of mean-level changes found (Jackson et al., 2012; van Scheppingen et al., 2016). The conclusion is that there are few experiences that one can point to that are reliably associated with personality trait change. 
Recently, there have been calls for an idiographic approach to change, where a person's personality is assessed and modeled relative to only him or herself (Beck \& Jackson, 2020ab; Cabrieto, Tuerlinckx, Kuppens, Hunyadi, \& Ceulemans, 2018; Jackson, Lord, Strube \& Harms, 2019; Wright et al., 2019). In regard to studying personality change, an idiographic approach alleviates concerns over how well broad, nomothetic models of personality capture individuallevel personality structure. Indeed, investigations into idiographic personality structure suggests that most individuals' personality structures do not match the Big Five (Beck \& Jackson, 2020a; Borkenau \& Ostendorpf, 1998; Molenaar, 2004). Thus, investigations of personality change may be better served by investigating change relative to an individual's unique personality structure. In the present study, we apply a new technique for testing for correlational (structural) change in idiographic personality using a yearlong intensive longitudinal study of personality.

\section{Idiographic Personality Assessment}

Nomothetic approaches parsimoniously describe between-person personality structure, but some researchers continue to call for more idiographic approaches that bring the person back into the study of psychology and personality processes (Beck \& Jackson, 2020ab; Beltz, Wright, Sprague, \& Molenaar, 2016; Cervone, 2005; Fisher, 2015; Grice, 2004; Molenaar, 2004; Wright

et al., 2019; Wright \& Woods, 2020). From this perspective, broad nomothetic measures of personality miss important differences in individual-level structure. Indeed, Allport $(1937 ; 1968)$ famously advocated for the importance of idiographic approaches to personality, arguing that "true" personality traits only existed at the level of individuals. In his view, between person "common" traits captured what was universal or shared but would always be necessarily accompanied by measurement error because the "true" idiographic trait would never be fully captured. As he defined it, "Personality is the dynamic organization within the individual of 
those psychophysical systems that determine [sic] his unique adjustments to [sic] his environment" (Allport, 1937, p. 42).

A number of components of Allport's (1937) definition are of note. First, he writes that personality is organized within an individual. Within-person investigations are vital to understanding personality beyond the fact that it was a key condition in early theoretical models of personality traits, in part because of an assumption that the between-person structure would replicate within individuals (Borsboom et al., 2003). If the between person structure replicates within a person then the processes that drive differences between people are likely the same processes occurring within a person. However, in a notable demonstration (Nesselroade \& Molenaar, 2001), only one-third of the sample showed a personality structure similar to the between person, population estimate. For the remaining two-thirds, an alternative structure of personality was needed. Similarly, Grice (2004) examined how well nomothetic measures of the Big Five could capture idiographically derived personal constructs and found that at least half of the variability in individual differences relied on the idiographic personal constructs. Similar studies find that the within-person structure of personality both differs from the between-person structure and that people's within-person structure differs from one another (Beck \& Jackson, 2020a). Together these findings suggest that understanding personality requires identifying the structure of manifestations of personality at the level of a person, not a population.

Second, Allport writes that personality is a dynamic organization of psychophysical systems. Thus, rather than advocating for a view of personality as a static trait, Allport saw these as dynamic characteristics that must and will vary across time and contexts as well as people. Indeed, Allport never intended traits to be studied in isolation, writing that "no trait operates alone" (Allport, 1937, p. 330). Moreover, he later formalized many of these dynamic ideas by 
offering an open systems theory of personality (Allport, 1960). In recent years, interest in studying psychological phenomena as dynamic, interdependent systems has grown dramatically, with network approaches, for example, garnering considerable attention, with some touting the great advantages these models offer (Borsboom \& Cramer, 2013) as well as some of the downfalls (Forbes et al., 2017; although see Borsboom et al., 2017 for a contrasting opinion), particularly in cross-sectional research that static relationships among indicators.

Considering idiographic personality from a dynamic systems perspective is a promising method for studying personality as a dynamically organized system for two reasons. First, idiographic models that can be represented as networks necessarily require repeated assessments of an individual over time in order to estimate the models - that is, they require dynamic data. Second, dynamic systems approaches and network tools highlight relationships among indicators within the model, visually and quantitatively representing complex relationships between indicators that reveal both direct and indirect relationships between them. Moreover, dynamic systems approaches to idiographic modeling are better suited to answering questions of intraindividual personality processes that are not easily testable within factor models (see Beck \& Jackson, 2017, 2020ab). From a dynamic systems perspective, an organization or structure captures a system's current state, its most common state, and its typical patterns of short-term change (i.e. its dynamics).

Finally, Allport (1937) argued that changes in the dynamic organization were expected as “adjustments to [sic] his environment." Thus, changes in environments should be expected to result in changes in the organization of an individual's personality system, rather than necessarily evidenced in the overall mean levels of personality characteristics. As a result, we may both expect that changes in environments predict changes in organization and vice versa (Allport, 
1960). Despite this, structural changes in personality have rarely been investigated (see Beck \& Jackson, 2021a), with most studies that have doing so at the nomothetic level (e.g., Jackson \& Beck, 2021).

\section{Personality Change}

An idiographic approach to the study of personality change offers the opportunity to address gaps in the extant literature. Typically, personality development examines rank-order or mean-level change, both of which are variable-centered measures, rather than individual or person-centered measures. More rarely, personality development considers ipsative change, which gets closer to individual-level change by examining personality profiles across time (Jackson \& Beck, 2021; Roberts, Wood, \& Caspi, 2008; Robins, Fraley, Roberts, \& Trzesniewski, 2001).

While ipsative change is often referred to as person-centered, given that each person gets an estimate of consistency, there are some shortcomings. Most notably, it does not examine changes in a dynamic structure, such as that theorized in Allport's definition of personality. From this perspective, personality should be conceived as an interdependent system where the personality characteristics may influence one another, which a growing body of research supports (Beck, Condon, \& Jackson, 2021; Christensen, Golino, \& Silvia, 2020; Schwaba, Rhemtulla, Hopwood, \& Bleidorn, 2020). Both longitudinal and cross-sectional evidence suggests that personality change occurs structurally, rather than just in terms of levels of trait. For example, a recent study showed cross-sectional structural differences of Big Five scales across the lifespan, with younger but not older adults exhibiting a clear Big Five structure (Beck et al., 2021). In older adults, this is largely explained by strong relationships between indicators of putatively different traits. In other words, the Big Five do not show independent 
developmental patterns, and indicators of putatively different traits may show strongly correlated developmental trajectories. Together, this suggests that to understand personality development, one needs to examine it from a narrower perspective, such as idiographically.

To date, only two studies have examined longitudinal change in idiographic personality represented as a network (Beck \& Jackson, 2020a; 2021b). In both studies, participants completed two waves of intensive repeated measures either one year apart (Beck \& Jackson, 2020a) or up to one year before the onset of the COVID-19 pandemic and after its onset (Beck \& Jackson, 2021b). Idiographic time series models were estimated for each participant of withinperson relationships between indicators of four (Beck \& Jackson, 2020a) or five (Beck \& Jackson, 2021b) of the Big Five and ipsative consistency was estimated between the profile relationships over the two waves. Within-person contemporaneous (same time point) relationships showed strong consistency over time in both studies, on average, but there were interindividual differences in intraindividual change, indicating that although many people were quite consistent, some people were almost nothing like their former self. Unfortunately, because participants were measured across waves and not continuously, it is not possible to isolate when over the course of time participants first showed changes in their personality.

From a systems perspective, changes in the connections within a system can be strong predictors of larger, cascading effects on system functioning. When there are more and stronger relationships among components of a system, small perturbations at the level of one component can have catastrophic, wide-ranging consequences. Consider, for example, the 2003 North American Blackout. During the blackout, there was widespread power outage in parts of the Northeast and Midwest in the United States as well as in Ontario, Canada. In total, approximately 55 million people lost power (see Barabási, 2017). The cause of the blackout was 
a software bug at single station in Akron, Ohio. What followed is an example of vulnerability due to interconnectivity. With the station in Akron down, the load of producing and transporting electricity that usually fell on that station was shifted to other stations. This led to a cascading effect, where the redistribution sequentially overloaded a number of stations, which redistributed more of the load to the remaining stations and overloaded them as well. Because of this, a seemingly small glitch in software in Ohio was able to knock out power for millions of people.

There is well-documented evidence that the Big Five are not as well differentiated as was originally thought (e.g., Christensen et al., 2020; Schwaba et al., 2020). Beginning in even the earliest days in which the Big Five became the dominant model of between person differences, some of the pioneers in assessment noted the lack of simple structure of the Big Five traits - that is, their tendency to correlate with one another. Thus, Hofstee, De Raad, and Goldberg (1992) proposed the AB5C model, which is a circumplex model of personality in which it is assumed that certain items will load highly onto multiple traits. Similarly, evidence from the study of personality development suggests robust patterns of correlated change (e.g., Allemand, Zimpric, \& Martin, 2008; Klimstra et al., 2013) - the tendency for different traits to exhibit similar interindividual patterns of intraindividual change - indicating that personality traits are associated with one another rather than orthogonal.

Thus, both idiographic and between-person studies of the Big Five indicate that personality characteristics both tend to be associated with one another and tend to be differentially associated across people, which raises the question of whether the degree and pattern of interconnectivity in these psychological systems is associated with similar patterns of vulnerability that other interconnected systems, like a power grid, do. Consider, for example, the simple personality system visualized in Figure 1a. In this individual's system, the characteristics 
are relatively independent - the lines representing their relationships are relatively sparse and thin, indicating that the existing relationships are relatively weak. Thus, if this person shows a boost in Conscientiousness, this might weakly impact their Extraversion and Neuroticism, but the effect would likely be small and overall change at the level of the system would likely not be enduring. Considered like dominoes, if one tips over, the others will remain upright (Cramer et al., 2016). In contrast, the individual in Figure $1 \mathrm{~b}$ has many and strong connections among their personality characteristics in the system. In this case, even a small boost in Conscientiousness is going to impact each of the other traits to differing degrees. Moreover, the connection strength is likely strong enough that those traits will then influence the others in a series of cascading effects similar to the Northeast Blackout in 2003. Small changes in this system may have long term and far reaching effects - tipping over one domino will bring the others down with it. In case, the changes reflected in correlations between the indicators, which indicates changes in the variance and covariance of the indicators that have been previously linked to system-level change. In one study, for example, increasing temporal autocorrelation, variance, and correlations among statelevel measures of emotions predicted the onset of major depressive episodes (van de Leemput et al., 2014). 

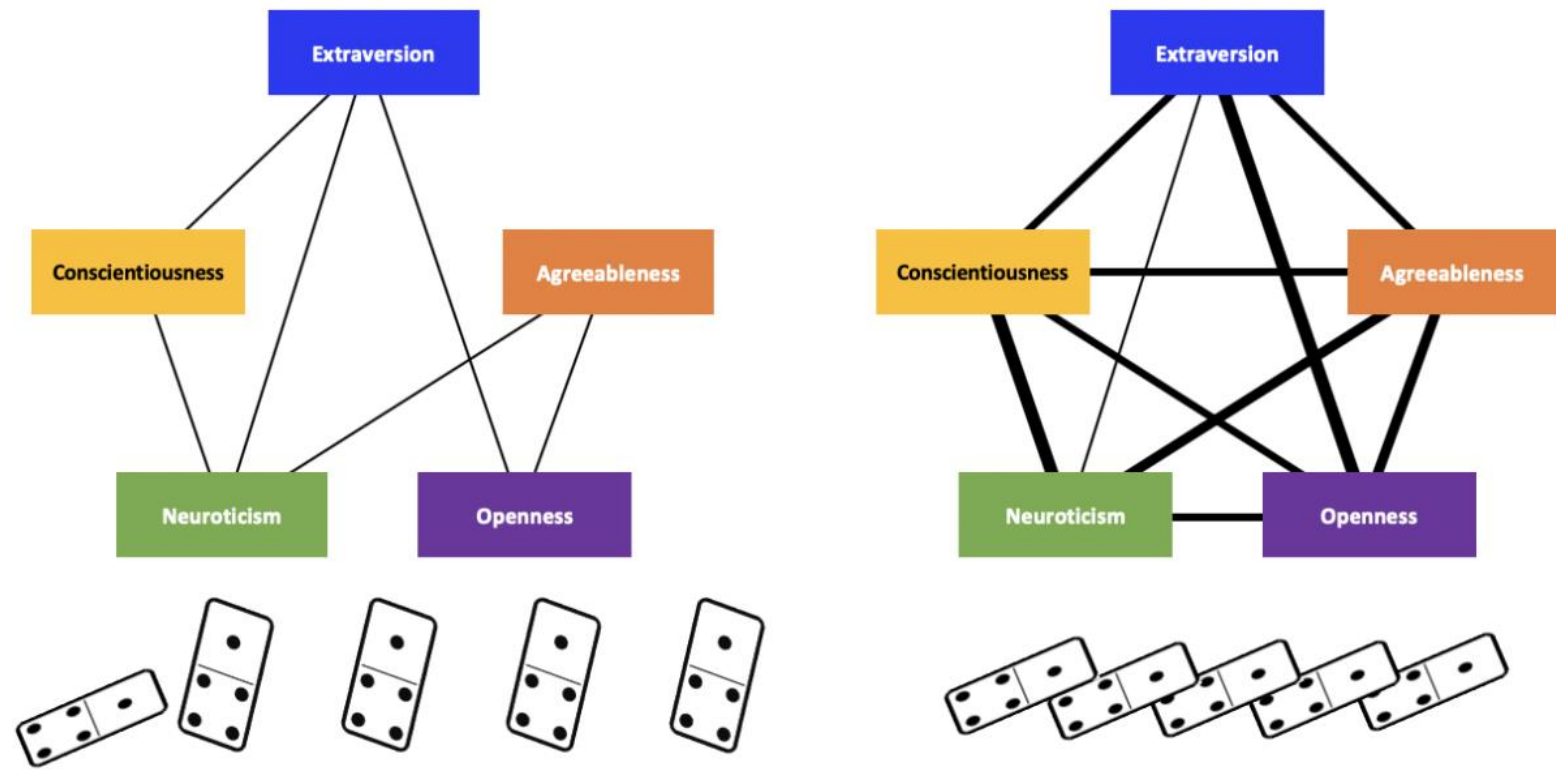

Figure 1. Two hypothetical correlational structures of the Big Five for two individuals. (1A): A loosely connected (low density) system in which perturbations in one component will have little impact on others (i.e. if one domino falls, the others will not follow). (1B): A strongly connected (high density) system in which perturbations in one component will have strong impact on others (i.e. if one domino falls, the others will follow).

Additional research on the study of systems suggests that cascading changes are particularly important when considering states of equilibria within a system. Systems tend to exist at states that are close to equilibria - that is, components of the system tend to have set points that govern the push and pull of a system toward or away from those points. True equilibria of the system as a whole would exist when all of the components of a system are at a set point. However, many systems have multiple possible equilibria, particularly if components of the system have multiple set points, which is common for psychological phenomena (see Butner, Gagnon, Geuss, Lessard, \& Story, 2014). To move to a different set point, great and often sustained perturbations from a component's set point is necessary. In other words, to move to a different equilibrium, multiple components will have to move to a new point. In the example of the Northeast Blackout, the stations had two set points - working or not. The Blackout did not take down every station. Instead, the system found a new equilibrium, where many, but not all 
stations, were down. Moreover, the more densely connected a system is, the less movement or force that will be needed to push a system from one equilibrium to another.

\section{The Present Study}

The current study examines changes in idiographic personality systems in a large sample of individuals using preregistered methods. Detecting changes in psychological systems can be difficult because until recently, the methods for collecting the requisite intensive time series data and modeling them using a robust technique for detecting change in the system were not available. Recently, with the expanding use of online, computerized assessment of personality, collecting intensive data has become much easier and available. Moreover, the recent introduction of a method for detecting correlational changes in multivariate time series using a permutation based significance test for kernel change point $(\mathrm{KCP})$ technique has made it possible to more robustly test for changes systems of times series data (Cabrieto, Tuerlinckx, Kuppens, Hunyadi, \& Ceulemans, 2018). In the present study, we combine the two to test whether we can detect idiographic personality system change and whether the timing of that change is associated with life events. This novel perspective offers an alternative method for investigating personality change compared to the ubiquitous mean level change.

\section{Method}

This study was preregistered on the Open Science Framework prior to any analysis of the data (osf.io/zbkta) and all data, code, and results are available on OSF (osf.io/mfn8w/) and GitHub (github.com/emoriebeck/KCP).

\section{Participants}

Participants were 388 undergraduates (135 F, 252 M, 1 unknown) involved in romantic relationships at the University of Illinois, Urbana-Champagne. On average, participants were 
22.60 years old $\left(S D_{a g e}=6.28\right)$. Of the 388 participants, $280(72.16 \%)$ self-reported as white, 57 (14.69\%) as Asian, 21 as Hispanic (5.41\%), 15 as Black (3.87\%), and three as “other" (0.77\%). $12(3.09 \%)$ did not report their race or ethnicity or provided an answer that made did not make sense in the context of the question, such as "exclusive"). Participants completed weekly surveys over the course of one year and were offered $\$ 150$ in compensation for their time. In total, there were 15,355 responses. On average, participants responded to 40.2 surveys $(\mathrm{SD}=14.9$, range 1 to 55).

\section{Materials and Procedure}

All data were collected as part of a larger study on attachment style and relationships. Each week for one year, participants responded to questions about attachment style in different relationship contexts, the Big Five (the TIPI; Gosling, Rentfrow, \& Swann, 2003), relationship satisfaction, and relationship / life events were collected. In addition, each wave included one of the five following surveys at random: depressive symptoms (CESD), ECR-R attachment, Big Five personality traits (BFI), attachment features and functions (WHOTO), physical health symptoms (PILL). Data from this study have been published elsewhere (Fraley, Vicary, Brumbaugh, \& Roisman, 2011), but in the present investigation will use data concerning weekly personality and life / relationship events with a novel analytic procedure not used with this data prior.

Personality. Personality was measured using the Ten Item Personality Inventory (TIPI; Gosling et al., 2003). Each of the Big Five included two items, one positively (e.g. the Extraversion item "I see myself as: Extraverted, enthusiastic") and one negatively (e.g. the Extraversion item "I see myself as: Reserved, quiet") keyed. Participants responded to each item on a Likert-like scale from 1 (strongly disagree) to 7 (strongly agree). 
Life Events. Life events were measured with checkbox items indicating whether an event had occurred (coded as 1) in the last week or not (coded as 0 ). We included seven life / relationship events, including a family member passing away, being separated from a partner due to travel, finding out that one was pregnant, getting engaged, moving in together, getting married, and breaking up with a partner. As indicated in our preregistration, we created a variable that indexes whether participants experienced any of the events and which week they occurred. We tested both this broader composite and specific life events' relationship to change points.

\section{Data Analysis Plan}

Analyses were based a permutation-based kernal change point (KCP) analysis for detecting correlational changes in multivariate time series (Cabrieto et al., 2018). The full analysis plan, as well as all code, which is set up as a set of functions that allow for easy user input, were preregistered on the Open Science Framework (osf.io/zbkta) and are available on OSF and GitHub. The online materials include animated visualizations of each step of the procedure for explanatory purposes (emoriebeck.github.io/KCP). The procedure is idiographic that is, it was conducted for each participant separately.

The KCP procedure involves eight steps, ${ }^{1}$ which we will detail below:

1. Moving window correlations.

2. Gaussian similarity between all possible phases for different $k$.

3. Calculate the average within-phase variance of Gaussian similarity.

4. Repeat steps 1 to 3 for 1000 permuted data sets.

\footnotetext{
${ }^{1}$ Our preregistration included six steps. The eight steps included here represent splitting the calculation of Gaussian similarity and average within-phase variance into two separate steps and an additional step for locating the location of the change points that was unintentionally omitted due to a fuller discussion of it existing in a separate paper.
} 
5. Perform the Variance Test.

6. Perform the Variance Drop Test.

7. Declare significance if either Variance Test or Variance Drop Test passes.

8. Keep $k$ of minimum penalized average within-phase variance.

Moving window correlations. The first step involved calculating the correlations among all variables using a moving window. Essentially, this involved breaking down the total number of time points into $N-2$ windows, or phases (see Figure 2a). Then, the correlation among all variables was calculated within each phase, effectively sliding the window across the full time series and resulting in $N-2$ correlations. The resulting correlations can be represented as a time series of correlations between variables (see Figure 2b). For an animated representation of this procedure, see the online materials (emoriebeck.github.io/KCP). We used a window size of 10 and ran 1000 permutations.
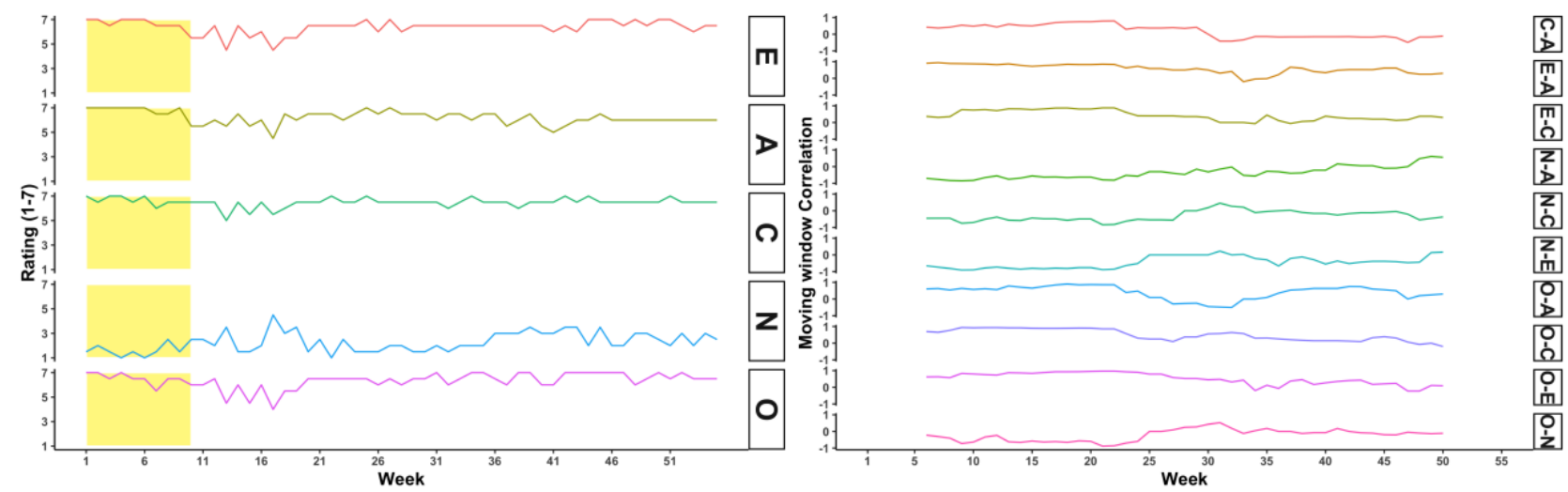

Figure 2. Raw time series (2A) and moving window correlation time series (2B) for one example participant. The $\mathrm{x}$-axis represents week in the study, the $\mathrm{y}$-axis is the rating on a 1 to 7 scale in the left panel and a correlation (-1 to 1$)$ in the right panel. Rows in the left panel capture trait composites, while rows in the right panel capture combinations of traits. The box in 1A captures the window that slides across the time series, capturing the correlations among observations therein. $\mathrm{E}=$ Extraversion, $\mathrm{A}=$ Agreeableness, $\mathrm{C}=$ Conscientiousness, $\mathrm{N}=$ Neuroticism, and $\mathrm{O}=$ Openness.

Gaussian similarity. The goal of the KCP procedure is to break time series down into phases that are broken apart by change points. Essentially, this means that the moving window 
correlations within a phase should be very similar to one another but different from correlations in other phases. Thus, the next step of the procedure involved calculating the similarity between the moving window correlation matrices at each moving window. To do so, we used a measure of Gaussian similarity:

$$
G k\left(\mathbf{R}_{i}, \mathbf{R}_{j}\right)=\exp \left(\frac{-\left\|\mathbf{R}_{i}-\mathbf{R}_{j}\right\|^{2}}{2 h_{R}^{2}}\right)
$$

where $\mathbf{R}$ represents the correlation matrix, $i$ and $j$ represent windows within the time series, and $h$ is obtained by computing the median Euclidean distances between all $\mathbf{R}_{i}$ 's.

Thus, we ultimately had a set of all pairwise Gaussian similarities for each window, which we used to calculate how variable correlations are.

Average within-phase variance. Once we had the Gaussian similarities, the next step was to calculate the average variance within all possible sets of phases $(k+1$; see Figure 3 to see examples of $k=0$ to $k=3$ phases). Because the algorithm searches for the optimal number of change points, we did not specify this advance but constrained the maximum number of change points to three, as we believed this to be the maximum number of plausible changes over one year of weekly assessments. Thus, we test $k=0,1,2,3$, meaning that we test up to 3 possible change points $(k)$, which indicates up to 4 phases in the time series. Average within-phase variance was calculated as:

$$
\hat{R}\left(\tau_{1}, \tau_{2}, \ldots, \tau_{K}\right)=\frac{1}{n} \sum_{p=1}^{K+1} \widehat{V}_{p}, \tau_{1}, \tau_{2}, \ldots, \tau_{K}
$$

where $n$ is the number of phases, $\tau_{1}, \tau_{2}, \ldots, \tau_{K}$ represent the locations (where $\tau_{K}$ is the change point, making it the last observation of a phase) of the possible change points (when $k=$ 
0 , then this is simply the last window), $K$ is the number of the change points, $n=K+1$, and $\widehat{V}_{p}$ is the within phase variance for each phase $(p)$, calculated as:

$$
\hat{V}_{p}, \tau_{1}, \tau_{2}, \ldots, \tau_{K}=\left(\tau_{p}-\tau_{p-1}\right)-\frac{1}{\tau_{p}-\tau_{p-1}} \sum_{i=\tau_{p-1}+1}^{\tau_{p}} \sum_{j=\tau_{p-1}+1}^{\tau_{p}} G k\left(\mathbf{R}_{i}, \mathbf{R}_{j}\right)
$$

where $\tau_{p}-\tau_{p-1}$ indicates the size of the phase because $p$ indicates the last observation of the current phase and $p-1$ the last observation of the previous phase.

Thus, we were left with a set of $\hat{R}$ 's indicating the average within-phase variance of similarity between moving window correlations for all possible sets of phases for $k=0,1,2,3$, which we next used to find the most homogeneous set of phases.
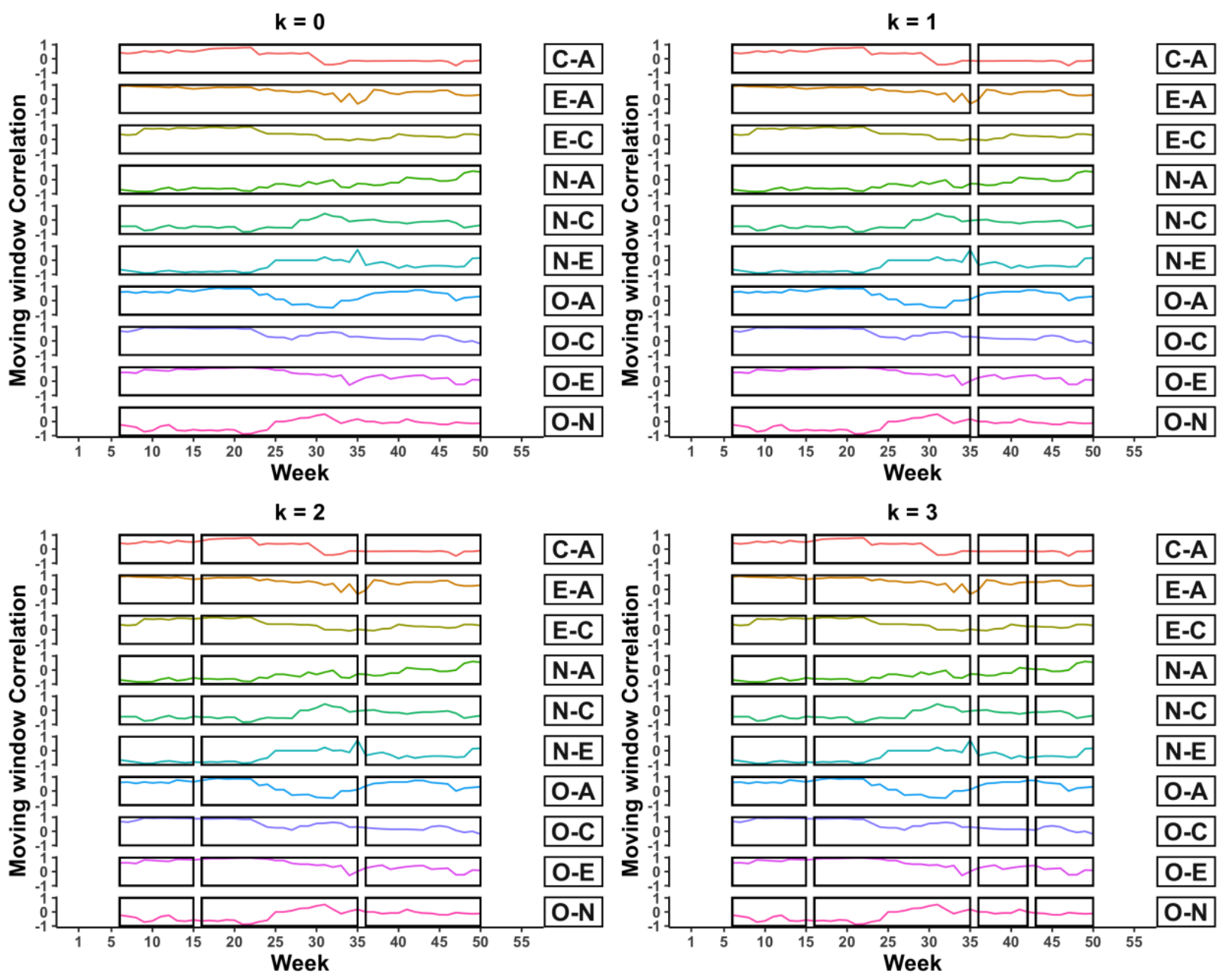
Figure 3. Sample moving window correlation time series with 0 to 3 knots (i.e. 1 to 4 phases). Week is on the $\mathrm{x}$-axis, moving window correlations (-1 to 1) are on the y-axis, and different rows indicate all unique combinations of traits. Boxes indicate each unique phase, meaning that knots occur at the breaks between boxes.

Permutations. Before we could determine the most reliably homogeneous phases, we needed a criterion for determining this. The $\mathrm{KCP}$ procedure uses two permutation-based tests to determine whether the average within-phase variance we see for different sets of phases is larger than we would expect by chance. Thus, the next step involved repeating steps 1 to 3 on 1000 permuted (i.e. shuffled without replacement) data sets. This resulted in 1000 sets of $\hat{R}_{\text {perm }}$ 's to which to compare the empirical $\hat{R}$ 's.

Variance Test. The Variance Test tests whether the variance in moving window correlation similarity across observations within a window exceeds chance variability in permutations (shuffles) of the data set. This indicated whether there were any change points in the data. If there were, the variance in moving window correlations should be greater in the raw data than in the permuted data sets, according to:

$$
P_{\text {variancetest }}=\frac{\#\left(\hat{R}_{\min , K=0}>\hat{R}_{\min , K=0, \text { perm }}\right)}{B}
$$

where $\hat{R}_{\min , K=0}$ is the average within phase variance when there was no change point (i.e. using the full time series) and $B$ was the number of permutations.

Stated more simply, the variance test indexes whether the variability in the correlations across the full time series exceeded what we would expect by chance. If it did, then we can assume this means the variability was non-random and at least one change point existed.

Variance Drop Test. The Variance Drop Test, in contrast, is meant to account for the fact that as more phases are added, the average within-phase variance necessarily decreases, even if there was no real change point in the data. In other words, it tested whether adding change 
points reduces the variability more than we would expect by chance when adding additional change points, according to:

$$
P_{\text {variancedroptest }}=\frac{\#\left(\max \text { variance } \text { drop }_{\text {perm }}>\max \text { variance } d r o p\right)}{B}
$$

where the max variance drop $=\widehat{R}_{\min , K}-\widehat{R}_{\min , K-1}$, for both raw and permuted data, and $\mathrm{B}$ indicates the number of permutations.

Making a decision. The inference criterion for each test is $P_{\text {variancetest }}$ and $P_{\text {variancedroptest. }}$ In both cases, the range will be between 0 and 1, where higher values indicated support for a change point in the time series. Because we conducted two inferential tests, we used a Bonferonni correction and declare that there is at least one change point if either exceeded .975 .

Finding change point locations. If no change points were found, then the final step of finding the location of a change point is skipped. If either the Variance Test or Variance Drop Test as significant, then the number and location of the change points needed to be determined. To do so, we used a procedure for choosing $k$ that includes a penalty that penalizes for the complexity that additional change points introduce, such that:

$$
\widehat{K}=\arg \min \hat{R}_{\min , K}+\operatorname{pen}_{K}
$$

where $\hat{R}_{\min , K}$ was the average within phase variance and $p e n_{K}$ was defined as

$$
\text { pen }_{K}=C \frac{V_{\text {max }}(K+1)}{n}\left[1+\log \left(\frac{n}{K+1}\right)\right]
$$

where $K$ is the number of change points, $\mathrm{n}$ is the number of observations, $C$ is a tuning parameter that controls the level of penalty (defined below), and $V_{\max }$ is computed by taking the trace of the first and last $5 \%$ of observations in each time series separately and keeping whichever is larger. 
As is clear in the formula, as $K$ increases, each piece of the formula becomes larger keeping all other terms constant, meaning that the penalty increases with more changepoints $k$. As is also clear, the tuning parameter $C$ can strongly impact the penalty term as it is a direct multiplier. To choose $C$, we used a grid search procedure. To begin, we set $C=1$ and find the minimized $\widehat{K}$ value. Whatever $k$ was associated with this minimized value was retained and $C$ was incremented by 1 and the procedure was repeated until the associated $k$ becomes 0 . The actual value $k$ and the location of the change points was determined by finding the modal set of change points and phases and the associated $k$.

Relationship to life events. As a follow up, we tested whether identified change points coincide with life event experiences. It was possible that only a small subset of the population would show reliable change points. Of those that showed change points, it was likely that only a subset would report one of the 7 life events we collected. Of those that both showed change points and reported at least one life event, we report the proportion of individuals whose life event experiences fall +/- 2 weeks from the empirically derived change points.

\section{Results}

\section{Do Participants Exhibit Change Points?}

First, we tested how many participants exhibited any change points across the year (i.e. 52 weeks). Of the 301 participants with enough data points to conduct the $\mathrm{KCP}$ procedure, 59 (19.6\%) exhibited at least one change point, with the remaining $246(80.4 \%)$ of participants showing no change points. Of the 59 participants who showed at least one change point, 43 $(14.3 \%)$ showed one change point, while $16(5.3 \%)$ showed two change points. No participants demonstrated three change points. 
Thus, although a majority of participants did not appear to show changes in the structure of their personality over one year, a non-trivial number did show change. Below, we will walk through the results of three participants who showed either 0,1 , or 2 change points. Then, we will end the discussion by examining whether the events people experienced tended to coincide with KCP identified change points. Demographic characteristics for the three sample participants are in presented in Table 1 along with each of their means, standard deviations, minima, and maxima in Table 2.

\section{No Change Points: Participant 109}

Participant 109 was a female, aged 20, who identified as White and was in an exclusive relationship. She responded to 52 surveys. Her raw time series is shown in Figure 4a. As is clear from Table 2, she consistently reported higher Agreeableness, Conscientiousness, and Openness, on average, and lower Extraversion and Neuroticism. Openness was her least variable trait.

Participant 109 experienced several events throughout the course of the year of the study. She reported her partner was traveling during 11 of the 52 weeks, as well as that she and her partner became engaged in week 3 and were married in week 38.

Table 1

Demographic Characteristics and KCP Procedure Results for Sample Participants

\begin{tabular}{cccccccc}
\hline Participant & Gender & Age & $\begin{array}{c}\text { Relationship } \\
\text { Type }\end{array}$ & Ethnicity & $\boldsymbol{k}$ & $\begin{array}{c}\text { Knot } \\
\text { Location }\end{array}$ & $\begin{array}{c}\text { Penalty } \\
(\boldsymbol{C})\end{array}$ \\
\hline 109 & Female & 20 & Exclusive & White & 0 & & \\
202 & Female & 21 & Engaged & White & 1 & 38 & 177 \\
087 & Female & 22 & Married & White & 2 & 10,14 & 84 \\
\hline
\end{tabular}

Table 2

Descriptive Statistics for Sample Participants

\begin{tabular}{cccccccccccccc}
\hline & \multicolumn{4}{c}{$\mathbf{1 0 9}$} & \multicolumn{1}{c}{$\mathbf{2 0 2}$} & \multicolumn{4}{c}{$\mathbf{0 8 7}$} \\
\cline { 2 - 14 } Trait & M & SD & Min & Max & M & SD & Min & Max & M & SD & Min & Max \\
\hline Extraversion & 3.88 & 0.61 & 2 & 5 & 6.20 & 0.32 & 5.5 & 7 & 5.21 & 0.83 & 3 & 6.5 \\
Agreeableness & 6.20 & 0.61 & 5 & 7 & 4.55 & 0.77 & 3 & 6 & 6.21 & 0.38 & 5.5 & 7
\end{tabular}




\begin{tabular}{rcccccccccccc} 
Conscientiousness & 5.89 & 0.77 & 4.5 & 7 & 3.54 & 0.42 & 2.5 & 4 & 5.20 & 0.53 & 4 & 6.5 \\
Neuroticism 2.69 & 0.79 & 1 & 4.5 & 1.52 & 0.46 & 1 & 2.5 & 3.19 & 0.76 & 2 & 5.5 \\
Openness 5.91 & 0.44 & 5.0 & 7.0 & 5.39 & 0.70 & 3.0 & 7.0 & 6.73 & 0.32 & 6 & 7.0 \\
\hline
\end{tabular}
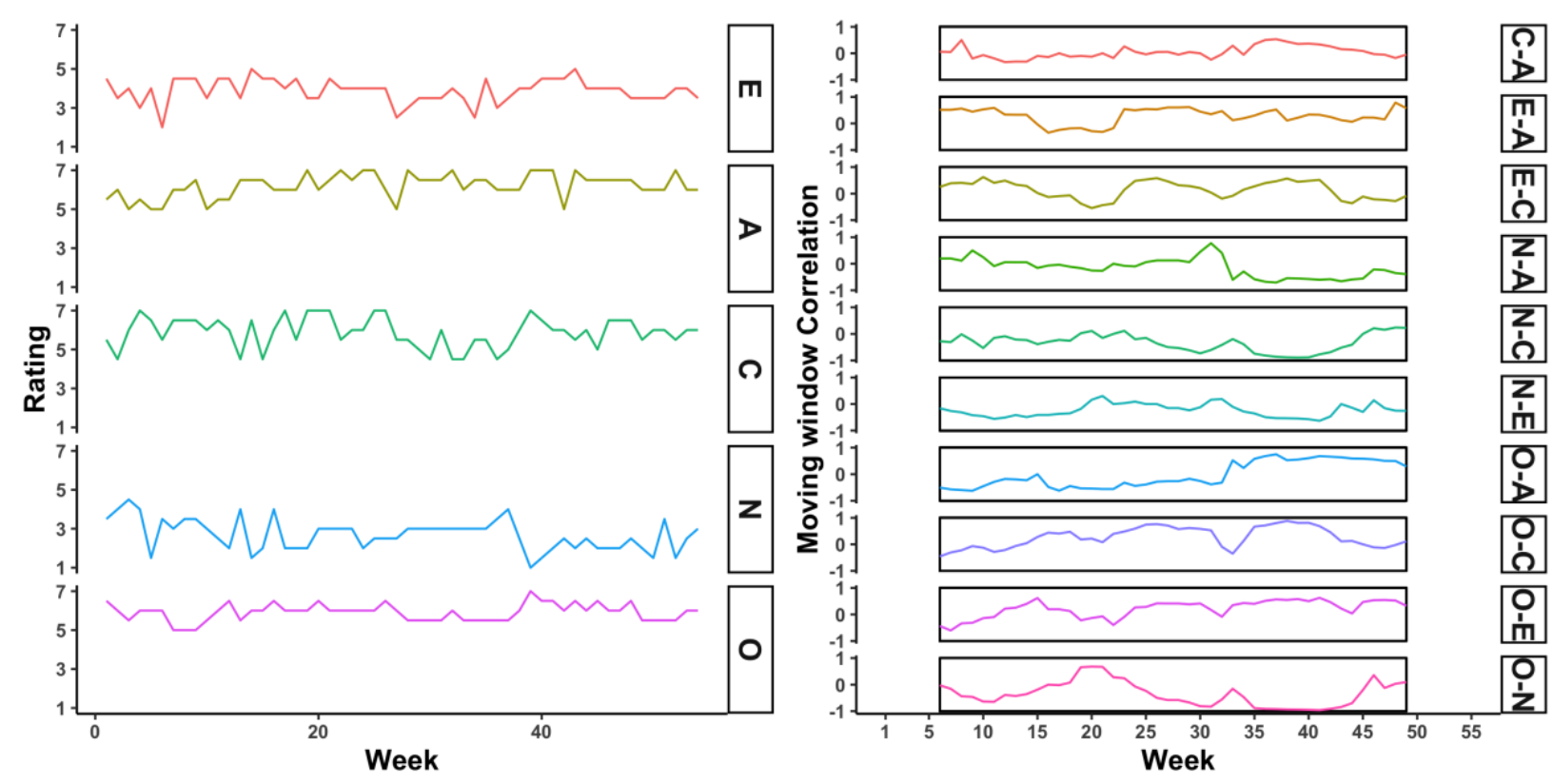

Figure 4. Raw and moving window correlation time series for participant 109, who should one phase (no change points). The $\mathrm{x}$-axis represents week in the study, the $\mathrm{y}$-axis is the rating on a 1 to 7 scale in the left panel and a correlation (-1 to 1) in the right panel. Rows in the left panel capture trait composites, while rows in the right panel capture combinations of traits. $\mathrm{E}=$ Extraversion, $\mathrm{A}=$ Agreeableness, $\mathrm{C}=$ Conscientiousness, $\mathrm{N}=$ Neuroticism, and $\mathrm{O}=$ Openness .

Despite the events she experienced over the course of the study, as shown in Figure 4b, which depicts the time series of moving window correlations for participant 109, the KCP procedure detected no correlational change points in the time series $(k=0)$. As can be seen in the figure, there was variation in the moving window correlations across the times series. However, variation alone does not mean there will be change points in the time series because the $\mathrm{KCP}$ procedure tests whether such variation is more than we would expect by chance. In this case, the variation did not exceed chance levels, so the procedure detected no change points.

\section{One Change Point: Participant 202}


Participant 202 was a 21 year old female who identified as White and was engaged. She responded to 47 surveys. Figure 5a shows her time series, and Table 2 shows her within-person descriptive statistics for each of the Big Five. Throughout the study period, Participant 202 reportedly being consistently Extraverted, with her average score ranging between 5.5 and 7 .

Despite this, as can be seen in the time series, she did show consistent week to week variation in Extraversion as well as the rest of the Big Five. Participant 202 reported a great number of life events, specifically that her partner was traveling for all but one of the surveyed weeks.


Figure 5. Raw and moving window correlation time series for participant 202, who should one phase (no change points). The x-axis represents week in the study, the y-axis is the rating on a 1 to 7 scale in the left panel and a correlation (-1 to 1) in the right panel. Rows in the left panel capture trait composites, while rows in the right panel capture combinations of traits. $\mathrm{E}=$ Extraversion, $\mathrm{A}=$ Agreeableness, $\mathrm{C}=$ Conscientiousness, $\mathrm{N}=$ Neuroticism, and $\mathrm{O}=$ Openness.

Unlike Participant 109, Participant 202 exhibited one correlational change in her time series. The one week he was not traveling, however, was not the point at which she demonstrated a correlational change point in her time series, so it seems unlikely the change could be attributed to that. The moving window correlation time series for Participant 202 is displayed in Figure 5 b. The Variance Test was not significant $(p=1)$, but the Variance Drop Test was significant $(p=$ 
$.001)$. The procedure for finding the location of the change point showed one change $(k=1)$

point at 38 weeks $(C=177)$. Looking at the two phases, it becomes clear that the correlations do appear to either increase or decrease around week 38 and remain consistently at that level. Given that the KCP procedure is essentially searching for sets of phases in which the correlations are quite homogeneous within relative to what we would expect from the permuted data, the location of the change point does differentiate the end of the time series, where we see the moving window correlations become quite flat and smooth, from the beginning of the time series, which is somewhat more variable.

\section{Two Change Points: Participant 087}

Participant 087 was a 22 year old White female and married. She responded to 54 surveys. Her demographic information is in Table 1, and her within-person descriptive statistics are in Table 2. Unlike both Participant 109 and Participant 202, Participant 087's within-person means were at or above the mid-point (4) for each of the Big Five. She reported the highest Conscientiousness of the three sample participants. Participant 087 reported a few life events. During weeks 7 and 8, she reported losing a family member, and during weeks 11, 14, and 27, she reported her partner was traveling. 

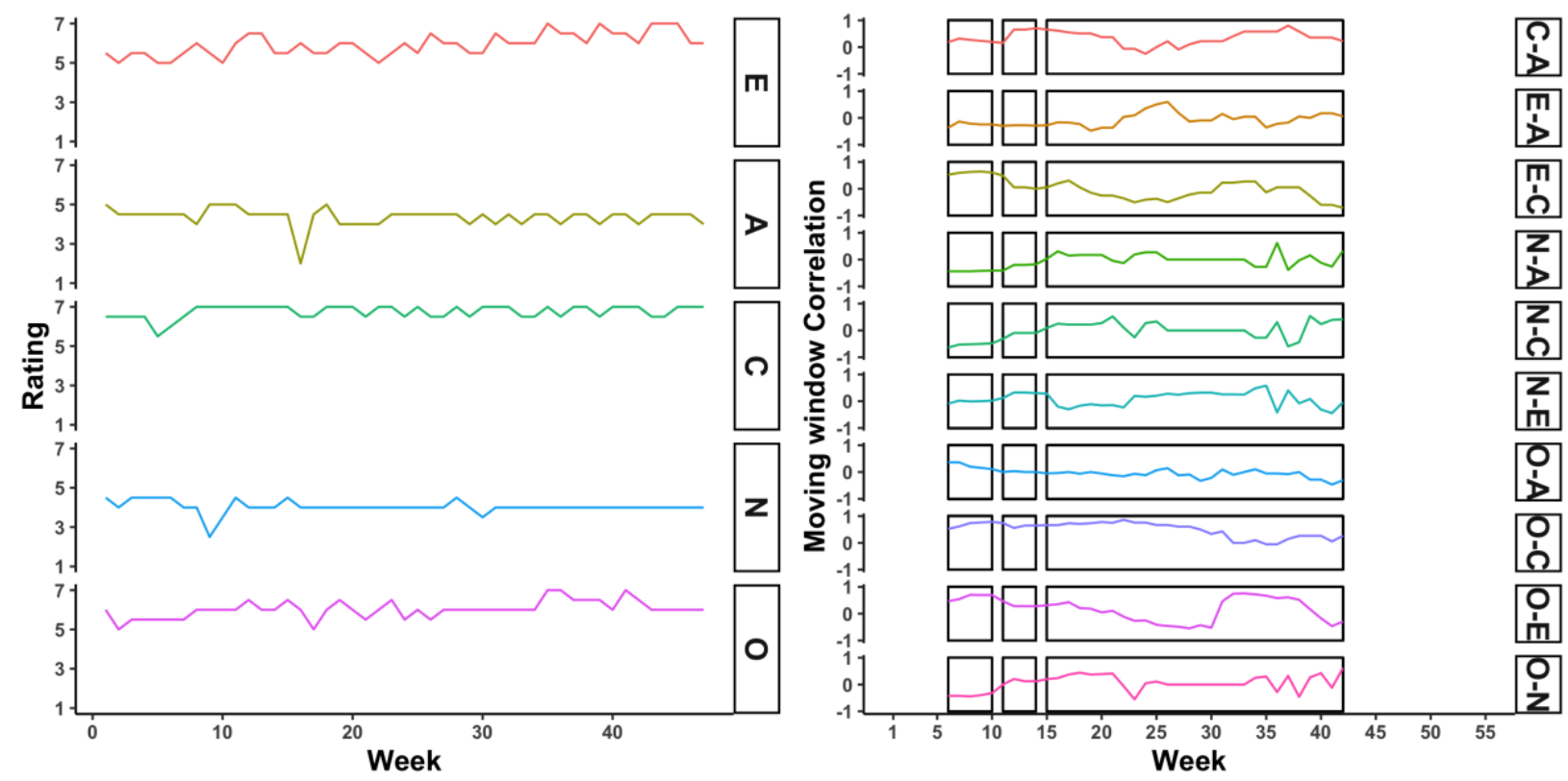

Figure 6. Raw and moving window correlation time series for participant 087 , who should one phase (no change points). The $\mathrm{x}$-axis represents week in the study, the $y$-axis is the rating on a 1 to 7 scale in the left panel and a correlation (-1 to 1) in the right panel. Rows in the left panel capture trait composites, while rows in the right panel capture combinations of traits. $\mathrm{E}=$ Extraversion, $\mathrm{A}=$ Agreeableness, $\mathrm{C}=$ Conscientiousness, $\mathrm{N}=$ Neuroticism, and $\mathrm{O}=$ Openness.

The Variance Drop Test $(p=.007)$ but not the Variance test $(p=.73)$ indicated that Participant 087 had at least one change point. The procedure for testing the number and location of the change points indicated that she showed two correlational change points in her time series $(k=2)$, at week 10 and 14 weeks, respectively $(C=84)$. Despite the relatively short time frame of change, it is clear from Figure $6 \mathrm{~b}$ that there is a clear and consistent change in the level of the correlations at both of these locations. As with Participant 202, such a breakdown makes sense given that the KCP procedure is minimizing the within-phase variance in correlational similarity, which is clearly quite small in the first two phases. Notably, the timeline of these changes line up reasonably well with both the period after losing a family member as well as when her partner was traveling, so it is possible that the change in the correlational time series reflects true changes in her experiences during those times.

\section{Relationship to Life Events}


Finally, in a set of preregistered exploratory analyses, we tested whether the life events participants reported weekly coincided with the empirical change points found using the KCP procedure. Total frequencies of different events, the number participants who experienced each event at least once, and descriptive statistics on the frequency with which participants experienced each event are presented in Table 3. The most frequently experienced event was a partner traveling, with one participant even reporting their partner traveled nearly every week.

Table 3

Descriptive Statistics of Weekly Events Participants Reported Experiencing

\begin{tabular}{|c|c|c|c|c|c|c|}
\hline \multirow[b]{2}{*}{ Event } & \multirow{2}{*}{$\frac{\text { Events }}{N}$} & \multicolumn{5}{|c|}{ Participants } \\
\hline & & $N$ & $M$ & $S D$ & Min & $\operatorname{Max}$ \\
\hline Death of a Family Member & 124 & 79 & 1.57 & 0.84 & 1 & 5 \\
\hline Partner Traveled & 3976 & 277 & 14.35 & 12.12 & 1 & 51 \\
\hline Separated from Partner & 133 & 85 & 1.56 & 0.97 & 1 & 6 \\
\hline Moved in with Partner & 49 & 33 & 1.48 & 1.48 & 1 & 9 \\
\hline Engagement & 33 & 27 & 1.22 & 0.58 & 1 & 3 \\
\hline Married & 20 & 19 & 1.05 & 0.23 & 1 & 2 \\
\hline Pregnancy & 10 & 10 & 1.00 & 0.00 & 1 & 1 \\
\hline Any Event & 4222 & 290 & 14.56 & 11.99 & 1 & 51 \\
\hline
\end{tabular}

Note. $N$ for Events is the total frequency of events reported, while $N$ for Participants is the total number of participants who reported each event at least once. $M, S D$, Min, Max are the descriptive statistics among participants who reported experiencing those events.

Because participants reported whether events had occurred in the last week, we tested whether the week the participant reported the event fell within $+/-2$ week of the empirical change points. The number and proportion of events that did are presented in Table 4. As can be seen in the table, the overall prevalence of many of these events were quite small and the great majority of the events that were observed did not fall within the approximately one month 
window of we examined. Thus, it appears that the change points that were detected were not associated with the events that were measured.

Table 4

Proportion of Events that Matched with Empirical Correlational Change Points

\begin{tabular}{rcccc}
\hline & \multicolumn{2}{c}{ Matched } & \multicolumn{2}{c}{ Unmatched } \\
\cline { 2 - 5 } Event & $\boldsymbol{N}$ & $\mathbf{\%}$ & $\boldsymbol{N}$ & $\mathbf{\%}$ \\
\hline Death of a Family Member & 2 & 9.52 & 19 & 90.48 \\
Partner Traveled & 110 & 12.67 & 758 & 87.33 \\
Separated from Partner & 3 & 10.34 & 26 & 89.66 \\
Moved in with Partner & 0 & 0.00 & 3 & 100.00 \\
Engagement & 1 & 16.67 & 5 & 83.33 \\
Married & 0 & 0.00 & 2 & 100.00 \\
Pregnancy & 0 & 0.00 & 2 & 100.00 \\
Any Event & 114 & 12.47 & 800 & 87.53 \\
\hline
\end{tabular}

Note. Only Participants with at least one empirical correlational change point are included in this table.

\section{Discussion}

In the present study, we sought to test changes in personality at the idiographic, personlevel from a dynamic systems perspective. Building from the observation that there are individual differences in changes in personality levels (e.g., Mroczek \& Spiro, 2003) and from evidence that personality characteristics are not independent within- or between-person (e.g., Allport, 1937; 1968; Beck \& Jackson, 2020a; Beck et al., 2021; Christensen et al., 2020; Schwaba et al., 2020), we applied a permutation-based kernel change point method for detecting correlational change in multivariate time series (Cabrieto et al., 2018) using weekly assessments of personality collected across the course of one year. Results indicate that a non-trivial number of participants showed at least one change point in their personality system during the one year timespan and that those change point(s) tended to be at different points in individuals' time series. However, the change points had little relationship to life events that participants reported 
experiencing. We discuss below how this novel method provides unique insights into personality development and assessment.

\section{Personality Change}

Personality development is most often examined through changes in absolute, mean levels or through differential consistency (Roberts, Wood, \& Caspi, 2008). These two forms are only two potential ways to investigate how personality develops across the lifespan out of many (see Jackson \& Beck, 2021). The current paper provides a novel conceptualization of change within personality. We investigated the inter-relationships among personality constructs, focusing at the individual, idiographic level. Our conceptualization of change thus asks about the relative importance of constructs within a person across time. Previously, this individual developmental approach has been examined through ipsative, profile approaches (Donnellan, Conger, \& Burzette, 2007) as well as idiographic, network approaches (Beck \& Jackson, 2020a).

Unique to our approach is that personality development also incorporates variance among the constructs. For example, it is possible to have similar rank ordering of psychological variables within a person but have greater or less variance during certain windows of time. While changes in variance are rarely examined (though see Jackson \& Beck, 2021; Mõttus, Allik, Hřebíčková, Kööts-Ausmees, \& Realo, 2016; Schwaba \& Bleidorn, 2018 for exceptions), those that have examined such changes in variance have done so at the single construct level. In contrast, our novel approach examines variance across sets of personality characteristics. Together, taking an individual approach combined with examining variance, allows this novel perspective to better identify shocks to the personality system, whereby changes indicate a disruption in the normal status of personality. 
We identified nearly $20 \%$ of people had a change point within the year; thus, $80 \%$ of people were consistent within their personality. What does it mean to change over the course of weeks? Most studies of personality examine change over longer periods of time such as years and decades (e.g., Damien et al., 2019). While changes across a one year time period have been found (e.g., Richert et al., 2020), they are often investigated with much coarser assessment of change (i.e. monthly or longer intervals between assessments) making it difficult to know how quickly the change occurs. Here we found that changes were abrupt from one week to the next, indicating that personality development may not be as slow and gradual a process as most theories postulate (Roberts \& Jackson, 2008; Specht et al., 2014, Wrzus \& Roberts, 2017).

However, identifying change in personality does not mean it persists. For example, some have argued that changes over the short term are state-artifacts, reflecting only short-term changes in states rather than longer term changes in traits (see Roberts et al., 2017, for a review). For example, changes could be induced by a vacation or a rough week at the office, after which they may have reverted to their original configuration. From this perspective, any changes observed should return to "normal," perhaps because their environment shifted, which in the present study would be reflected by participants who showed change points showing two (or more) change points. While these situational based descriptions of personality change are common, the current study found that the majority of people did not revert to their original personality system. Of those $20 \%$ that showed any change points, only a quarter (5\% of the total sample) had the second necessary change point necessary for them to have "reverted." Instead, the most common form of change was lasting change, perhaps again indicating that change observed over longer time periods is not due to gradual change but instead short-lasting "growth spirts" common in physical development. 
While our current approach is set up to identify shocks and perturbations to the system at a level of precision narrower than many past studies (i.e. weekly), we did not identify widespread effects of life events. This could occur for at least three reasons. First, life events can sometimes be anticipated (e.g., Denissen, Luhmann, Chung, \& Bleidorn, 2019; van Scheppingen et al., 2016). Thus, the true start of life events does not occur at the objective start of the life event. This is true for a number of life events we examined, such as when one's partner traveled. Even seemingly unexpected events, like the death of a loved one, can be anticipated in many occasions from health-related processes like terminal decline (e.g., Mueller, Wagner, Wagner, Ram \& Gerstorf, 2019). Second, we may not have focused on the correct life events, as this study was focused on investigating romantic couples. Given that few life events are capable of reliably changing personality across people, it is thus not entirely surprising that we found minimal associations.

Finally, our current approach examined personality development at a different time scale than standard life event and personality development investigations (e.g., Bleidorn, Hopwood, \& Lucas, 2018; Jackson et al., 2012; Specht et al., 2011). It is possible that the processes driving personality development do not emerge at the weekly timescale used in the current study. While there are numerous calls to coordinate the granularity of life events assessment with the type of change processes expected (e.g., Luhmann et al., 2014; Hopwood, Wright \& Bleidorn, 2021), they often conclude with the (correct) observation that current personality development studies have assessments spaced far apart and should assess personality and life events more frequently. The lack of influence of life events in the current study, despite the more granular assessment, suggests that either the time frame should narrow further or that life events do not impact everyone similarly. 


\section{Modeling Idiographic Personality}

The present study also stands unique in its use of an idiographic approach to personality change and development. Despite deep roots in the study of personality, idiographic personality remains relatively rarely examined and idiographic studies of change remain even rarer (see Beck \& Jackson, 2020a; 2021b; Jackson et al., 2019 for exceptions). In the present study, we tested a permutation-based kernel change point test for detecting changes in correlations (Cabrieto et al., 2018) among personality characteristics at the idiographic level. From Allport's (1937; 1960) definition of personality as a “dynamic organization” and open system to Cattell's (1943; 1946) data box and work on P-technique factor analyses, considering correlations among personality characteristics over time for a single individual is far from a new idea and has earned many names, such as idiographic structure, architecture (Cervone, 2005), the idioverse (Rosenzweig 1986), and more. However, despite the prevalence of idiographic correlations in both the theoretical and empirical literature, the present study was perhaps the first study to attempt to detect changes in those correlations.

We believe that capturing such correlational changes is important for several reasons. First, dynamic systems theory posits that such changes may signal that a system is close to a "tipping point," which can push the system to a new equilibrium that has consequences for both general system functioning and system output (e.g., Cramer et al., 2016; van de Leemput et al., 2014). These new equilibria may correspond to the onset of a mental health event, such as the onset of a major depressive episode. One goal of detecting such changes may then to be use them apply just in time adaptive interventions (JITAI; e.g., Wang \& Miller, 2019). In personality, there is growing interest in using time series of personality to better understand health (see Jackson \& Beck, 2020 for an overview). Thus, given evidence that longitudinal changes in 
personality are associated with, for example, dementia diagnoses (e.g., Balsis, Carpenter, \& Storandt, 2005; Duchek, Balota, Storandt, \& Larsen, 2007) and mortality (Mroczek \& Spiro, 2007), techniques like the permutation-based approach used in the present study may be useful for understanding when individuals show changes in personality that signal changes in either physical or mental health.

Second, much as the study of personality change and development has increasingly recognized the importance of time in capturing change (e.g., Luhmann et al., 2014; Hopwood, Wright \& Bleidorn, 2021), the study of dynamic systems emphasizes the importance of time. Thus, in the present study, we used data that captured a narrower bandwidth of time in order to better capture the dynamic aspects of personality where people generally describe themselves once a week for a year. Thus, the correlations - and changes in them - reflect idiographic patterns of variability in the levels of different personality characteristics - i.e. idiographic personality structure - over the course of a year. We believed that the bandwidth of such weekly assessments was much more likely to capture the timing of changes in the dynamic aspects of personality characteristics than typical annual, biennial, or even longer intervals between assessments. At the same time, there is well-documented evidence that personality states also vary over the course of seconds, minutes, hours, and days and that there are carry-over effects of personality states over all of these time frames. Thus, to best capture idiographic personality structure as the "dynamic organization" and "open system" that Allport $(1937 ; 1960)$ and others (e.g., Baumert et al., 2017; Read \& Miller, 2002; Revelle \& Condon, 2015) have argued for, capturing personality at even narrower bandwidths and examining more dynamic associations among personality characteristics and states may further delineate both what and how idiographic personality structure changes over time. 


\section{Densely Connected Systems and Tipping Points}

In the present study, we took an idiographic, dynamic systems approach to personality, testing for changes in the idiographic structure of personality. Specifically, we drew on a systems-based phenomena wherein densely connected systems, like those favored by and selected for by traditional personality methods like factor analysis, are actually vulnerable to change (e.g., Barabási, 2016; Cramer et al., 2016; van de Leemput et al., 2014; Wichers et al., 2016). From this perspective, when elements in a system are densely connected, changes in one element can have cascading effects, redistributing the overall load of the system in ways that can have dramatic consequences for downstream elements. Much as in a number of blackouts in which the power grid is largely taken down as burden at power stations are sequentially increased past capacity until they are taken offline (Barabási, 2016), elements in a psychological system may be sequentially overwhelmed until the whole system shifts or individual elements may simply change their "load" until the load of other elements changes similarly.

For a person, vulnerability by interconnectivity and cascading effects may be seen as "acting off," perhaps in the form of flat affect, overly intense affect, and feelings of general instability. In some cases, as discussed in previous sections, this could reflect short-term state fluctuations associated with experiences or environments, like taking a vacation or a particularly stressful week. Such shifts may, in turn, have positive or negative social, work or school, economic, and psychological consequences that either reinforce system stability or change (see Magidson \& Roberts, 2014; Wrzus \& Roberts, 2017). Indeed, as we saw in the present study, such shifts may be more enduring (see also Roberts et al., 2017), with the subset of participants who showed any change points slightly more likely to have one change point over the course of the year than two. Moreover, among those who experienced two change points, the middle phase 
tended to be relatively short, suggesting that participants with two change points were "pushed back" to their original equilibria. Thus, in general, change was relatively rare, but for those who did experience change, it tended to be - but was not always - more enduring.

That only a minority of participants exhibited one or more change points indicates the utility of the permutation-based kernel change point method. There is little reason to suspect that a large proportion of a population in a passively observed study should exhibit changes in their personality over the course of one year that reaches almost any threshold of statistical detection. But, in some contexts, changes in personality are desirable because of the strong link between levels of a personality characteristic and outcomes (e.g., Beck \& Jackson, 2021c). Thus, the KCP procedure could be used in the context of intentional personality intervention studies and other classes of intervention studies as a source of continuous monitoring of intervention efficacy (e.g., Fahrenberg, Myrtek, Pawlik, \& Perrez, 2007; Olthof et al., 2020). Critically, if it were possible to more precisely delineate the timing of change, this could improve our ability to probe participants experiences at the point of change with more precision and fidelity, which may help to elucidate the processes and impetuses of personality change.

\section{Limitations and Future Directions}

The present study tested a permutation-based kernel change point method for detecting correlational change points in multivariate time series of personality data from a dynamic systems perspective (Cabrieto et al., 2018), finding that a non-trivial number of participants demonstrated change points. Although we overall found the procedure to be a useful and valid tool, the study was limited in a number of ways, many of which suggest areas for future study.

First, it is possible that assuming that the Big Five should be necessary and sufficient to capture personality at the level of the person is unlikely at best and wholly incorrect at worst 
(e.g., Beck \& Jackson, 2020a; Condon et al., 2021; Mõttus et al., 2020). Stated simply, if we examine changes among only narrow composites of Big Five characteristics from the TIPI, any changes in associations between other experiences and characteristics cannot and will not be observed. Particularly, from a person-centered, idiographic perspective in which not all items are assumed to have the same relevance for all people, not examining unique characteristics and experiences may miss critical changes in an individual's personality. Thus, we think a critical next step is to examine changes in personality using similar intensive data collection procedures but with unique item sets.

Second, in the present study, personality was assessed weekly for a year by asking participants to rate themselves in general at each occasion. Although response styles are always of interest in such observational studies (e.g., Grimm \& Church, 1999; Harzing, 2006), when interested in change, this becomes even more important. If some participants responded to prompts considering how they are in general, even if it did not align with their current feelings or experiences, while others allowed current feelings and experiences to color their responses, then the resulting levels of personality characteristics reflect such response processes in addition to the target levels on these personality characteristics and make it difficult to capture change. In other words, such a procedure requires participants to both notice changes and acknowledge them as such (see Vazire, 2010; Vazire \& Carlson, 2011). Thus, future research investigating changes from different perspectives (e.g., partner, teacher, etc.) and response styles is necessary to tease apart patterns of change.

Third, we examined whether events corresponded to empirically detected correlation change points but found little correspondence. This may be because objective events are the wrong marker of a life event for several reasons. First, as mentioned previously, some events 
may be anticipated because travel is planned, loved ones health declines for months years before death, break-ups are anticipated from relationship problems, and other such occurrences, making the actual timing of the objective event perhaps the wrong marker in time. Second, just as individuals have individual differences in almost every daily experience, so too are there individual differences in subjective and objective responses to an event (e.g., Lyubomirsky \& Tucker, 1998). It is quite possible that an event like the death of family member may be devastating if with a close other but less so when the relationship was not close. Third, to the extent that events resulted in little to no behavioral or experiential changes for a participant, there is little reason to believe that an event would impact their personality (e.g., Wrzus \& Roberts, 2017). Thus, future studies of personality change and life events should endeavor to delineate whether events were anticipated, what individuals experienced in events' aftermath, and what and to what degree experiential and behavioral changes resulted from an event.

Fourth, from a dynamical systems perspective, personality characteristics can be thought of as attractor or equilibria states that are drawn back to those equilibria. Because equilibria can be identified by looking at the relationship between levels and change, an important next step in the study of correlational changes may be in testing how associations between changes in a system may change over time (see Danvers et al., 2020).

Fifth, the sample in the present study consisted of predominantly female college students at a rural midwestern university. Although a strength of such a sample is that college is a period of great change in which the number of individuals exhibiting change and the degree to which they exhibit change is typically thought to be more than at other points in the lifespan (e.g., Roberts, Walton, \& Viechtbauer, 2006; Soto, John, Gosling, \& Potter, 2011), this is also a weakness in that these results may not generalize to other age groups. For example, there is some 
evidence that in older adulthood, the structure of personality dedifferentiates, which may suggest that we would expect more individuals to exhibit change and to greater degrees (Beck et al., 2021). Moreover, which events may be relevant and how are also age-graded. Thus, the kernel change point method should also be tested in other age groups to determine whether and to what degrees changes are observed in order to better understand personality change across the lifespan (see Caspi, 1987).

\section{Conclusion}

In the present study, we tested a permutation-based kernel change point approach to detecting correlational changes in idiographic personality structure from a dynamic systems theory. We found that a non-trivial number of students exhibited one or more correlational change points, which we believe suggests its relevance for further investigations of individual differences in the type and degree of personality change. 


\section{References}

Allemand, M., Zimprich, D., \& Martin, M. (2008). Long-term correlated change in personality traits in old age. Psychology and Aging, 23(3), 545-557.

Allport, G. W. (1937). Personality: A psychological interpretation.

Allport, G. W. (1960). The open system in personality theory. The Journal of Abnormal and Social Psychology, 61(3), 301-310.

Balsis, S., Carpenter, B. D., \& Storandt, M. (2005). Personality change precedes clinical diagnosis of dementia of the Alzheimer type. The Journals of Gerontology Series B: Psychological Sciences and Social Sciences, 60(2), 98-101.

Barabási, A.-L. (2016). Network science. Cambridge: Cambridge University Press. ISBN: 97811070762661107076269

Baumert, A., Schmitt, M., Perugini, M., Johnson, W., Blum, G., Borkenau, P., ... \& Mõttus, R. (2017). Integrating personality structure, personality process, and personality development. European Journal of Personality, 31(5), 503-528.

Beck, E. D., Condon, D. M., \& Jackson, J. J. (2021). Interindividual age differences in personality structure. Manuscript under review.

Beck, E. D., \& Jackson, J. J. (2017). The search for a bridge: Idiographic personality networks. European Journal of Personality, 31, 530-532.

Beck, E. D., \& Jackson, J. J. (2020a). Idiographic traits: A return to Allportian approaches to personality. Current Directions in Psychological Science, 29(3), 301-308.

Beck, E. D., \& Jackson, J. J. (2020b). Consistency and change in idiographic personality: A longitudinal ESM network study. Journal of Personality and Social Psychology, 118(5), 1080-1100. 
Beck, E. D., \& Jackson, J. J. (2021a). Within-person variability. In The Handbook of Personality Dynamics and Processes (pp. 75-100). Academic Press.

Beck, E. D. \& Jackson, J. J. (2021b). Consistency of idiographic personality in the wake of COVID-19: A longitudinal ESM study. Manuscript under review.

Beck, E. D. \& Jackson, J. J. (2021c). A mega-analysis of personality prediction: Robustness and boundary conditions. Journal of Personality and Social Psychology.

Beltz, A. M., Wright, A. G., Sprague, B. N., \& Molenaar, P. C. (2016). Bridging the nomothetic and idiographic approaches to the analysis of clinical data. Assessment, 23(4), 447-458.

Bleidorn, W., Hopwood, C. J., \& Lucas, R. E. (2018). Life events and personality trait change. Journal of Personality, 86(1), 83-96.

Borkenau, P., \& Ostendorf, F. (1998). The Big Five as states: How useful is the five-factor model to describe intraindividual variations over time?. Journal of Research in Personality, 32(2), 202-221.

Borsboom, D., \& Cramer, A. O. (2013). Network analysis: an integrative approach to the structure of psychopathology. Annual Review of Clinical Psychology, 9, 91-121.

Borsboom, D., Fried, E. I., Epskamp, S., Waldorp, L. J., van Borkulo, C. D., van der Maas, H. L. J., \& Cramer, A. O. J. (2017). False alarm? A comprehensive reanalysis of "Evidence that psychopathology symptom networks have limited replicability” by Forbes, Wright, Markon, and Krueger (2017). Journal of Abnormal Psychology, 126(7), 989-999.

Borsboom, D., Mellenbergh, G. J., \& van Heerden, J. (2003). The theoretical status of latent variables. Psychological Review, 110(2), 203-219.

Butner, J. E., Gagnon, K. T., Geuss, M. N., Lessard, D. A., \& Story, T. N. (2015). Utilizing topology to generate and test theories of change. Psychological Methods, 20(1), 1-25. 
Cabrieto, J., Tuerlinckx, F., Kuppens, P., Hunyadi, B., \& Ceulemans, E. (2018). Testing for the presence of correlation changes in a multivariate time series: A permutation based approach. Scientific Reports, 8(1), 1-20.

Caspi, A. (1987). Personality in the life course. Journal of Personality and Social Psychology, 53(6), 1203-1213.

Cattell, R. B. (1943). The description of personality: Basic traits resolved into clusters. The Journal of Abnormal and Social Psychology, 38(4), 476.

Cattell, R. B. (1946). Description and measurement of personality.

Cervone, D. (2005). Personality architecture: Within-person structures and processes. Annu. Rev. Psychol., 56, 423-452.

Christensen, A. P., Golino, H., \& Silvia, P. J. (2020). A psychometric network perspective on the validity and validation of personality trait questionnaires. European Journal of Personality, 34(6), 1095-1108.

Condon, D. M., Wood, D., Mõttus, R., Booth, T., Costantini, G., Greiff, S., ... \& Zimmermann, J. (2021). Bottom up construction of a personality taxonomy. European Journal of Psychological Assessment.

Cramer, A. O., Van Borkulo, C. D., Giltay, E. J., Van Der Maas, H. L., Kendler, K. S., Scheffer, M., \& Borsboom, D. (2016). Major depression as a complex dynamic system. PloS one, 11(12), e0167490.

Damian, R. I., Spengler, M., Sutu, A., \& Roberts, B. W. (2019). Sixteen going on sixty-six: A longitudinal study of personality stability and change across 50 years. Journal of Personality and Social Psychology, 117(3), 674-695. 
Danvers, A. F., Wundrack, R., \& Mehl, M. (2020). Equilibria in personality states: A conceptual primer for dynamics in personality states. European Journal of Personality, 34(6), 9991016.

Denissen, J. J. A., Luhmann, M., Chung, J. M., \& Bleidorn, W. (2019). Transactions between life events and personality traits across the adult lifespan. Journal of Personality and Social Psychology, 116(4), 612-633.

Donnellan, M. B., Conger, R. D., \& Burzette, R. G. (2007). Personality development from late adolescence to young adulthood: Differential stability, normative maturity, and evidence for the maturity-stability hypothesis. Journal of Personality, 75(2), 237-264.

Duchek, J. M., Balota, D. A., Storandt, M., \& Larsen, R. (2007). The power of personality in discriminating between healthy aging and early-stage Alzheimer's disease. The Journals of Gerontology Series B: Psychological Sciences and Social Sciences, 62(6), 353-361.

Fahrenberg, J., Myrtek, M., Pawlik, K., \& Perrez, M. (2007). Ambulatory assessment-Monitoring behavior in daily life settings: A behavioral-scientific challenge for psychology. European Journal of Psychological Assessment, 23(4), 206-213.

Fisher, A. J. (2015). Toward a dynamic model of psychological assessment: Implications for personalized care. Journal of Consulting and Clinical Psychology, 83(4), 825-836.

Fisher, A. J., Medaglia, J. D., \& Jeronimus, B. F. (2018). Lack of group-to-individual generalizability is a threat to human subjects research. Proceedings of the National Academy of Sciences, 115(27), E6106-E6115.Forbes, M. K., Wright, A. G. C., Markon, K. E., \& Krueger, R. F. (2017). Evidence that psychopathology symptom networks have limited replicability. Journal of Abnormal Psychology, 126(7), 969-988. 
Fraley, R. C., Vicary, A. M., Brumbaugh, C. C., \& Roisman, G. I. (2011). Patterns of stability in adult attachment: An empirical test of two models of continuity and change. Journal of Personality and Social Psychology, 101(5), 974-992.

Gosling, S. D., Rentfrow, P. J., \& Swann Jr, W. B. (2003). A very brief measure of the Big-Five personality domains. Journal of Research in Personality, 37(6), 504-528.

Grice, J. W. (2004). Bridging the idiographic-nomothetic divide in ratings of self and others on the Big Five. Journal of Personality, 72(2), 203-241.

Grimm, S. D., \& Church, A. T. (1999). A cross-cultural study of response biases in personality measures. Journal of Research in Personality, 33(4), 415-441.

Harzing, A. W. (2006). Response styles in cross-national survey research: A 26-country study. International Journal of Cross Cultural Management, 6(2), 243-266.

Hofstee, W. K., de Raad, B., \& Goldberg, L. R. (1992). Integration of the Big Five and circumplex approaches to trait structure. Journal of Personality and Social Psychology, 63(1), 146-163.

Hopwood, C. J., Bleidorn, W., \& Wright, A. G. (2021). Connecting theory to methods in longitudinal research. https://doi.org/10.31234/osf.io/w5huz

Jackson, J. J., \& Beck, E. D. (2020). Using Ambulatory Assessments to Understand PersonalityHealth Associations. In Personality and Healthy Aging in Adulthood (pp. 93-110). Springer, Cham.

Jackson, J. J., \& Beck, E. D. (2021). Personality development beyond the mean: Do life events shape personality variability, structure, and ipsative continuity?. The Journals of Gerontology: Series B, 76(1), 20-30. 
Jackson, J. J., Lord, A. N., Strube, M. J., \& Harms, P. D. (2019). An idiographic approach to personality development: Examining change and consistency in self-concept. Available from psyarxiv.com/qdp98.

Jackson, J. J., Thoemmes, F., Jonkmann, K., Lüdtke, O., \& Trautwein, U. (2012). Military training and personality trait development: Does the military make the man, or does the man make the military? Psychological Science, 23 (3), 270-277.

Klimstra, T. A., Bleidorn, W., Asendorpf, J. B., Van Aken, M. A., \& Denissen, J. J. (2013). Correlated change of Big Five personality traits across the lifespan: A search for determinants. Journal of Research in Personality, 47(6), 768-777.

Luhmann, M., Orth, U., Specht, J., Kandler, C., \& Lucas, R. E. (2014). Studying changes in life circumstances and personality: It's about time. European Journal of Personality, 28(3), 256-266.

Lyubomirsky, S., \& Tucker, K. L. (1998). Implications of individual differences in subjective happiness for perceiving, interpreting, and thinking about life events. Motivation and Emotion, 22(2), 155-186.

Magidson, J. F., Roberts, B. W., Collado-Rodriguez, A., \& Lejuez, C. W. (2014). Theory-driven intervention for changing personality: Expectancy value theory, behavioral activation, and conscientiousness. Developmental Psychology, 50(5), 1442-1450.

McCrae, R. R., Costa, P. T., Jr., Terracciano, A., Parker, W. D., Mills, C. J., De Fruyt, F., \& Mervielde, I. (2002). Personality trait development from age 12 to age 18: Longitudinal, cross-sectional and cross-cultural analyses. Journal of Personality and Social Psychology, 83(6), 1456-1468. 
Molenaar, P. C. (2004). A manifesto on psychology as idiographic science: Bringing the person back into scientific psychology, this time forever. Measurement, 2(4), 201-218.

Mõttus, R., Wood, D., Condon, D. M., Back, M. D., Baumert, A., Costantini, G., ... \& Zimmermann, J. (2020). Descriptive, predictive and explanatory personality research: Different goals, different approaches, but a shared need to move beyond the Big Few traits. European Journal of Personality, 34(6), 1175-1201.

Mõttus, R., Allik, J., Hřebíčková, M., Kööts-Ausmees, L., \& Realo, A. (2016). Age differences in the variance of personality characteristics. European Journal of Personality, 30(1), 411.

Mroczek, D. K., \& Spiro III, A. (2003). Modeling intraindividual change in personality traits: Findings from the Normative Aging Study. The Journals of Gerontology Series B: Psychological Sciences and Social Sciences, 58(3), 153-165.

Mroczek, D. K., \& Spiro, A. (2007). Personality change influences mortality in older men. Psychological Science, 18(5), 371-376.

Molenaar, P. C., \& Nesselroade, J. R. (2001). Rotation in the dynamic factor modeling of multivariate stationary time series. Psychometrika, 66(1), 99-107.

Olthof, M., Hasselman, F., Strunk, G., van Rooij, M., Aas, B., Helmich, M. A., ... \& LichtwarckAschoff, A. (2020). Critical fluctuations as an early-warning signal for sudden gains and losses in patients receiving psychotherapy for mood disorders. Clinical Psychological Science, 8(1), 25-35.

R Core Team (2018). R: A language and environment for statistical computing. R Foundation for Statistical Computing, Vienna, Austria. URL https://www.R-project.org/. 
Read, S. J., \& Miller, L. C. (2002). Virtual personalities: A neural network model of personality. Personality and Social Psychology Review, 6(4), 357-369.

Revelle, W., \& Condon, D. M. (2015). A model for personality at three levels. Journal of Research in Personality, 56, 70-81.

Richter, J., Zimmermann, J., Neyer, F. J., \& Kandler, C. (2020). Do Sojourn Effects on Personality Trait Changes Last? A Five-Year Longitudinal Study. European Journal of Personality.

Roberts, B. W., \& DelVecchio, W. F. (2000). The rank-order consistency of personality traits from childhood to old age: a quantitative review of longitudinal studies. Psychological Bulletin, 126(1), 3-20.

Roberts, B. W., \& Jackson, J. J. (2008). Sociogenomic personality psychology. Journal of personality, 76(6), 1523-1544.

Roberts, B. W., Luo, J., Briley, D. A., Chow, P. I., Su, R., \& Hill, P. L. (2017). A systematic review of personality trait change through intervention. Psychological Bulletin, 143(2), $117-141$.

Roberts, B. W., \& Mroczek, D. (2008). Personality trait change in adulthood. Current Directions in Psychological Science, 17(1), 31-35.

Roberts, B. W., Walton, K. E., \& Viechtbauer, W. (2006). Patterns of mean-level change in personality traits across the life course: A meta-analysis of longitudinal studies. Psychological Bulletin, 132(1), 1-25.

Roberts, B. W., Wood, D., \& Caspi, A. (2008). The development of personality traits in adulthood. Handbook of Personality: Theory and Research, 3, 375-398. 
Robins, R. W., Fraley, R. C., Roberts, B. W., \& Trzesniewski, K. H. (2001). A longitudinal study of personality change in young adulthood. Journal of Personality, 69(4), 617-640.

Rosenzweig, S. (1986). Idiodynamics vis-à-vis psychology. American Psychologist, 41(3), 241245.

Schwaba, T., \& Bleidorn, W. (2018). Individual differences in personality change across the adult life span. Journal of Personality, 86(3), 450-464.

Schwaba, T., Rhemtulla, M., Hopwood, C. J., \& Bleidorn, W. (2020). A facet atlas: Visualizing networks that describe the blends, cores, and peripheries of personality structure. PloS one, 15(7), e0236893.

Soto, C. J., \& John, O. P. (2012). Development of Big Five Domains and Facets in Adulthood: Mean-Level Age Trends and Broadly Versus Narrowly Acting Mechanisms. Journal of Personality, 80(4), 881-914.

Soto, C. J., John, O. P., Gosling, S. D., \& Potter, J. (2011). Age differences in personality traits from 10 to 65: Big Five domains and facets in a large cross-sectional sample. Journal of Personality and Social Psychology, 100(2), 330-348.

Specht, J., Bleidorn, W., Denissen, J. J., Hennecke, M., Hutteman, R., Kandler, C., ... \& Zimmermann, J. (2014). What drives adult personality development? A comparison of theoretical perspectives and empirical evidence. European Journal of Personality, 28(3), 216-230.

Specht, J., Egloff, B., \& Schmukle, S. C. (2011). Stability and change of personality across the life course: The impact of age and major life events on mean-level and rank-order stability of the big five. Journal of Personality and Social Psychology, 101 (4), 862-882. 
Terracciano, A., Costa Jr, P. T., \& McCrae, R. R. (2006). Personality plasticity after age 30. Personality and Social Psychology Bulletin, 32(8), 999-1009.

van de Leemput, I. A., Wichers, M., Cramer, A. O., Borsboom, D., Tuerlinckx, F., Kuppens, P., ... \& Scheffer, M. (2014). Critical slowing down as early warning for the onset and termination of depression. Proceedings of the National Academy of Sciences, 111(1), 8792.

van Scheppingen, M. A., Jackson, J. J., Specht, J., Hutteman, R., Denissen, J. J., \& Bleidorn, W. (2016). Personality trait development during the transition to parenthood: A test of social investment theory. Social Psychological and Personality Science, 7(5), 452-462.

Vazire, S. (2010). Who knows what about a person? The self-other knowledge asymmetry (SOKA) model. Journal of Personality and Social Psychology, 98(2), 281-300.

Vazire, S., \& Carlson, E. N. (2011). Others sometimes know us better than we know ourselves. Current Directions in Psychological Science, 20(2), 104-108.

Wang, L., \& Miller, L. C. (2019). Just-in-the-Moment Adaptive Interventions (JITAI): A MetaAnalytical Review. Health Communication, 1-14.

Wright, A. G. C., Gates, K. M., Arizmendi, C., Lane, S. T., Woods, W. C., \& Edershile, E. A. (2019). Focusing personality assessment on the person: Modeling general, shared, and person specific processes in personality and psychopathology. Psychological Assessment, $31(4), 502-515$.

Wrzus, C., \& Roberts, B. W. (2017). Processes of personality development in adulthood: The TESSERA framework. Personality and Social Psychology Review, 21(3), 253-277. 